PAPERS

\title{
The therapeutic implications of some recent research on trauma
}

\author{
H. B. STONER \\ MRC Trauma Unit, University of Manchester, Manchester
}

Seriously injured patients continue to arrive in accident and emergency departments in plenty. Some still die and many spend long periods in hospital recovering, sometimes incompletely. We have, perhaps, come to look on this as inevitable. Our senses deadened by the toll of the traffic, natural disasters, civil strife and the endless wars of varying size. With all these dramatic events it is easy to ignore all the injuries occurring in the home and at work. Although there have been improvements in their diagnosis and care for the most part the changes have not been fundamental. A possible exception to this is the use of computer-assisted tomography in the diagnosis of head injuries. Other examples of technical improvements are the diagnostic use of peritoneal lavage and the repair, rather than removal, of a ruptured spleen (Irving, 1983). The treatment of serious injury still rests, correctly, on resuscitation by fluid replacement and the removal and repair of damaged tissue, reduction of fractures, etc. at early operation. However, these simple principles that began to be formulated by Larrey during the Napoleonic wars (Dible, 1970) and which were reinforced during the Spanish Civil War and after by Trueta (1944), are not always fully understood and so not always carried out. Although there has been little further advance there has been an increasing volume of research, both clinical and experimental, into the nature of the responses to injury so that now is a good time to see if this work carries any therapeutic implications. Clinicians should read widely to glean information which they could put to practical use, for the basic scientist may not always be aware of the link. It is not possible in this paper to discuss the clinical implications of all the research of the last few years but in choosing topics an attempt has been made to illustrate a slightly different approach to the effects of trauma.

It has become customary to divide the responses to injury according to Cuthbertson's (1942) idea of an initial 'ebb' phase of depressed body function followed by a 'flow' phase of hypermetabolism. This was an important step since it led to appreciation of the importance of the time factor in the numerous changes which follow injury. However, this is not the only way to divide these responses for they can also be separated into those

Correspondence: Professor H. B. Stoner, MRC Trauma Unit, Stopford Building, University of Manchester, Oxford Road, Manchester M13 9PT 
which are related to the severity of the injury and those, unrelated to severity, which ars 'triggered' by injuries above a low severity threshold.

The therapeutic implications of these two types of response will be discussed, followed by a consideration of the impact of some other related research on the treatment of the्ष injured. In this context the severity of injury has been measured by the injury severit score (ISS) of Baker et al. (1974). This system has been widely tested and found adequatet for most purposes (Bull, 1975, 1978; Stoner et al., 1977, 1979, 1980).

Table 1 List of substances in plasma and urine whose concentration and daily output respectively increased with increasing severity of injury

\begin{tabular}{ccc}
\hline Ebb Phase & Flow Phase \\
Plasma & Urine \\
\hline Glucose & Creatine \\
Lactate & Total Nitrogen \\
Adrenaline & Creatinine & \\
Noradrenaline & & \\
\hline
\end{tabular}

\section{Responses which vary with the Severity of Injury}

The impact of an injury on the body is reflected in changes in both plasma and urifecte Some of these alterations are related to the severity of the injury, as graded by the ISfo and this relationship can be expressed in a number of ways. Some biochemical responses are continuously related, either linearly or exponentially, to the severity of the injury ove8

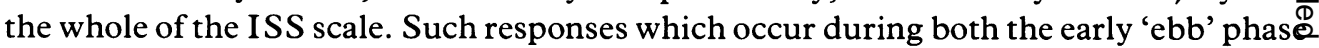
and the later 'flow' phase are listed in Table 1. A number of substrates and hormones i $\overrightarrow{\vec{\Phi}}$ the plasma show responses of this type during the 'ebb' phase. The log plasma glucose concentration, for instance, increases regularly as the severity of the injuries increase from minor, through moderate, to the very severe multiple ones (Stoner et al., 1979). The later changes in the urine which fall into this category are particularly important.

Not all the changes in the plasma constituents are related to the severity of the injuries in this way. For cortisol and the non-esterified fatty acids there is a positive relationshi as the severity increases from minor to moderate but further increases in severity are noछ associated with any further rise in the plasma concentrations, which may even fall wherg the injuries are very severe.

Except in the case of cortisol both types of relationship can be altered by the consumption of ethanol, usually before the accident. These effects, summarized in Tableू 2 , seem to imply that by lowering the redox state, as shown by the higher ketone body ratio, ethanol should make the patient's condition worse. Some features of severely injured patients seem to depend on the actual severity. In the 'ebb' phase, for instance, if the ISS exceeds about 30 the plasma insulin concentration is very low, presumablyo because its secretion is inhibited by adrenaline (Vigaš et al., 1973; Porte \& Robertson 1973).

Measurements of the respiratory exchange ratio $(\mathrm{RQ})$ shortly after injury (Little et al. 
1981) have shown that the main fuel being oxidized by the seriously injured patient (ISS $>12$ ) is fat. Patients with less severe injuries oxidize a more usual mix of substrates.

After severe injuries (ISS $>12$ ) the mean body temperature is depressed and the depression is linearly related to the ISS (Little \& Stoner, 1981).

Table 2 Effect of ethanol consumption on the responses in the plasma to injury in man

\begin{tabular}{ccc}
\hline Response decreased & Response increased & Response unchanged \\
\hline $\begin{array}{c}\text { Glucose } \\
\text { Non-esterified fatty acids } \\
\text { Glycerol }\end{array}$ & Lactate & Cortisol \\
\hline
\end{tabular}

Data from observations on injured patients with plasma ethanol concentrations 11-70 mmol/1 (Stoner et al., 1979)

\section{Therapeutic Implications}

No theory is needed to sense that it would be valuable to replace lost blood, remove irreparably damaged tissue and stabilize fractures. The positive relationship between ISS and the log plasma lactate concentration indicates that the more severe the injury the worse the oxygen supply to the tissues. If one can reduce the amount of the tissue damage, etc., associated with the injury as quickly as possible by the measures just mentioned one should improve the oxygen transport to the tissues during the 'ebb' phase and, hence, their performance. This reduction in the size of the injury is the fundamental aim of the counsels of Larrey and Trueta, although they may not always have realized it.

The positive relationship between ISS and the excessive excretion of creatine and nitrogen indicates that this plan of management could benefit the patient not only during the 'ebb' phase but also during the later 'flow' phase. Recent work on rats (Threlfall et al., 1983) has shown that the excess creatine in the urine comes from uninjured muscles as well as from those damaged by the injury. An early reduction in the size of the injury could thus also reduce the delayed metabolic changes which lead to the loss of weight and negative nitrogen balance and which can seriously delay recovery. This should be a major reason for wanting to reduce the size of the injury as the positive relationship between the severity of the trauma (ISS) and the size of the 'flow' phase response is much clearer than it was a few years ago. These results should be taken into account when deciding how far to go in trying to preserve a badly injured limb, for they favour amputation sooner rather than later (Annotation British Medical Journal, 1977; Threlfall et al., 1983).

- From experiments on rats (Stoner \& Matthews, 1967) and dogs (Kovách et al., 1970) the most likely explanation for the changes in the plasma non-esterified fatty acids concentration after injury is that when this is severe the fats depots are poorly perfused. Although lipolysis in the depots is stimulated by trauma (Stoner \& Matthews, 1967) the non-esterified fatty acids produced will not be swept out into the general circulation if plasma albumin is not available as a carrier. Since more fat than carbohydrate is oxidized shortly after severe injury (Little et al., 1981) this is a further reason for fluid replacement to correct the hypovolaemia and improve the circulation through the fat depots. 
It has not yet been decided whether the low plasma cortisol concentrations aft 8 severe injury (Stoner et al., 1979) are also due to poor circulation through the adrenals but it seems probable (Mack \& Egdahl, 1970). This could be another reason for vigorous flu侖 replacement since there does not seem to be any lack of ACTH in these patien (unpublished results).

There may be further implications in the plasma cortisol concentrations found in the injured patients. The concentrations are never very high and indicate less than maximgi stimulation of the adrenal cortex in most patients. Although the adrenal cortex plays 'permissive' role during the 'flow' phase it is more actively involved in the earlif responses. [It is thought by some (Alberti \& Johnston, 1977) that the active involveme of cortisol in the responses to injury can continue for some time after the 'ebb' phase.-. Experiments on rats (Barton \& Little, 1978; Barton \& Passingham, 1980; 1982) ha shown that increased glucocorticoid secretion is necessary to maintain the hype $\frac{\$}{3}$ glycaemia of injury and that the adrenal plays an important part in the compensation for. the fluid loss associated with limb ischaemia but not with haemorrhage. The reason for this difference is not yet known but inhibition of glucocorticoid secretion in the rat by trilostane increases the mortality after limb ischaemia. In experimental work the administration of glucocorticoids has often been shown to be of prophylactic but not therapeutic value (Lillehei et al., 1974). The exact role of the glucocorticoids in traum and sepsis is still far from clear and further research is urgently needed to define this role and the place of glucocorticoids in the treatment of trauma and sepsis. The irp discriminate use of massive doses of glucocorticoid is declining. There is a small groupiof patients in whom the response is deficient and who need replacement therapy. problem is to identify these patients easily and quickly so that they may be treate time.

As pointed out above the alterations in the biochemical responses to injury produce by ethanol consumption suggest that the patient's condition and prognosis would be aggravated by his intoxication and that steps should be taken to correct the situation, e.g. by gastric washout, fructose infusion, etc. Experiments on rats (Hadfield \& Stoner, 198 suggest that this is not a high priority. The real dangers of ethanol are the tradition ones. Ethanol not only increases the likelihood of the first accident but also the chances of a 'second accident', by increasing the difficulties of diagnosis and the dangers of airwa obstruction.

The fact that some 'flow' phase, as well as 'ebb' phase, changes are related to the severity of the injury is particularly interesting, especially as the increased urinary losses of creatine and nitrogen are related to the widespread metabolic effects of the injury. The implication of this is that later nutritional problems can be modified by the vigour of the. primary treatment in order to reduce the time during which the patient is hypovolaem and has untended injuries. The implications of current research for the nutritionab management of the injured patient will be discussed later.

\section{'Triggered' Responses}

Some of the responses set in motion by injury seem unrelated to the size of the injur $\frac{7}{6}$ Obviously the changes generated by a tiny scratch will always be less than those due t 
larger injuries but, provided the injury is large enough to cause significant responses, in some cases their size may be unrelated to the severity of the injury as measured by the ISS. Responses of this type are both biochemical and physiological and will be described as 'triggered' responses.

\section{Biochemical Responses}

Although there is a lot of research being done on the cellular responses to injury, the immunological changes, the effects on clotting mechanisms, on the reticulo-endothelial system and the complement system so far the therapeutic implications of this work are rather unclear. Many of these responses come within the category of 'triggered' responses since the initial injury sets off a cascade of enzymic reactions which multiplies the effect of the original stimulus.

However, one clear indication for treatment is the consumption of clotting factors in the coagulation cascade which can be corrected by appropriate infusions. Similarly, low serum fibronectin concentrations which can be found after trauma and which will interfere with the clearance of foreign matter from the circulation, can be corrected by giving cryoglobulin but it is difficult to say when this would be necessary. The importance of the reticulo-endothelial system in the recovery from injury is not yet established. Other cascades such as those concerned in the production of kinins and the degradation of complement are set in motion by injuries. We are not yet in a position to assess fully their significance.

After trauma to the body the liver produces, after 6-8 h (Colley et al., 1983), a whole range of proteins known as acute phase reactants. This is thought to follow the liberation of leucocyte endogenous mediator. Minor degrees of trauma seem to stimulate maximal production of acute phase reactants but as the function of most of these proteins is not yet known, the phenomenon does not stimulate ideas on therapy. Their main use may be as indicators of other biochemical events. Interest in leucocyte products has been recently increased by claims that they, or related substances, can lead to an increase in protein catabolism (Baracos et al., 1983; Clowes et al., 1983). It is too early to discuss therapeutic implications but if these claims can be substantiated there are a range of interesting possibilities since drugs are available which can affect the action of leucocyte pyrogens.

Another, rather different, biochemical response must be included in this category for the time being. Whatever happens to the plasma insulin concentration during the first few hours after injury, a few days later the concentration is raised, often to high levels. These do not produce the expected falls in the plasma glucose concentration and for a period of 7-10 days injured patients are in a state of insulin resistance, the degree of which is not obviously related to the severity of the injury. This effect lasts much longer in injured elderly patients and their immobility is probably one of the factors involved in this (Frayn et al., 1983).

The mechanism of this lack of sensitivity to insulin after injury is not yet understood. Work on the early stage of the response to trauma in the rat by Frayn (1977) and by Black et al. (1982) on the later stage in man indicates a change in the peripheral tissues, probably skeletal muscle, and is consistent with an intracellular post-receptor defect. 


\section{Physiological Responses}

The physiological responses which come within this category of 'triggered' response concern the nervous system and cover a wide range of its activities.

The Defence Reaction

Although injuries are accompanied by severity related increases in the activity of the adrenal medulla and peripheral sympathetic nervous system (Benedict \& Graham Smith, 1978; Davies \& Molyneux, 1982; K. N. Frayn, unpublished results) as shown b increases in plasma adrenaline and nonadrenaline concentrations, there may be ad explosive discharge of the sympathetic system around the time of the injury. This is the Defence Reaction (Folkow \& Neil, 1971) the stimulus for which is an appreciation of danger through the special senses. Acting through the amygdala, inhibition is removed from the Defence Area of the hypothalamus which then discharges to cause widesprea vasoaction, diverting blood from non-essential areas (e.g. skin) to more essential ones. Baroreceptor reflexes are inhibited so that the blood pressure can rise and, in some species, there is a cholinergic increase in muscle blood flow. This is a reaction designe for 'fight or flight' which persists for a variable time, gradually disappearing or tailing off into the reactions of the 'ebb' phase.

Homoeostatic Reflexes

In injury where the homoeostatic reflexes would seem of paramount importance it might be expected that any change in them would be towards an increase in their sensitivit 50 After simple fluid loss this is the case for it can be shown in both man and rat that moderate haemorrhage increases the sensitivity of baroreceptor reflexes (Little et 1983). However, simple haemorrhage is uncommon in trauma and when nocicep afferent impulses from damaged tissue are added the opposite changes are observed

Normally a homoeostatic reflex responds to changes in the system it controls, e. blood pressure, body temperature. However, these reflexes can be inhibited by nociceptive afferent impulses both in the case of the cardiovascular reflexes and thos concerned in thermoregulation. This has been shown in research on injured patients, o control subjects in whom nociceptive stimuli were generated by muscle ischaemia and on rats using the bilateral hind-limb tourniquet technique (Little \& Stoner, 1981; Little al., 1983; Redfern et al., 1983). The nociceptive afferent impulses which are n⿳亠丷厂犬 necessarily painful, probably reach the spinal cord in non-myelinated C-fibres. The ascend in the spinal cord to activate the interfering mechanisms in the hind-brain an hypothalamus. In some cases (Allen et al., 1973; Stoner, 1977; Stoner \& Marshall, 197 1982; Stoner et al., 1983) but not all, central catecholaminergic neurones are involvec. The mechanisms of these inhibitory effects are not known. Triggering is best seen in the inhibition of shivering by limb ischaemia in the rat where an effect lasting some hours determined by events during the first quarter of an hour after application of the tourniquets (Stoner \& Marshall, 1982).

Failure to understand the significance of these changes in homoeostatic behaviout limits the use which can be made of these results. Hunter (1794) considered the responsêf to injury to be defensive. At first sight it seems odd that inhibition of what are usualle considered defensive reflexes would itself be a defensive step against the insult of trauma? However, it is possible to build up a teleological argument in favour of this view (Stoner 1976) and there is some evidence for it (Stoner \& Marshall, 1975; Stoner, 1969, 1976 
Nevertheless, it may be that this response to trauma has been developed for an animal whose injuries will be untreated and met solely from its endogenous resources and that it could be dispensed with in a patient receiving modern treatment. Some evidence for this view is found in the rat. In the untreated rat after $4 \mathrm{~h}$ bilateral hind-limb ischaemia the optimum environmental temperature for survival is $20^{\circ} \mathrm{C}$ and raising that temperature to the thermoneutral $30^{\circ} \mathrm{C}$ will increase the mortality rate and shorten the survival time, although it will prevent the fall in body temperature. However, if the injured mouse or rat has been treated with large doses of $0.9 \% \mathrm{NaCl}$ the optimum environmental temperature for survival is $26^{\circ} \mathrm{C}$ and the fall in body temperature can be curtailed (Tabor \& Rosenthal, 1947).

Until the value of these fundamental responses has been fully assessed in the trauma patient who is being adequately resuscitated and whose injuries are receiving prompt surgical attention the use which can be made of our knowledge is limited. So long as the idea that they could be beneficial remains their simple reversal, if that were possible, might be unwise. Despite these caveats, however, some conclusions can be drawn.

The fact that these changes in reflex activity are found very soon after the injury emphasizes once more the need for speed in treatment both in respect of fluid replacement and the early treatment of wounds, correction of deformities, etc. to reduce nociceptive stimulation. This may mean that we should pay greater attention to the possibility of commencing treatment at the site of the accident. If so, who should do it, medical or paramedical people? In urban areas the 'scoop and run' policy will probably still be best if the patient can be delivered to an accident and emergency department in a few minutes. In country districts where it may take an ambulance $1-2 \mathrm{~h}$ to reach the patient and a similar period to get back to the hospital the position is obviously different. With this sort of delay before hospital treatment fluid replacement should be started and splinting, etc. to reduce nociception should be of value. The role of MAST trousers is discussed elsewhere (Randall et al., 1983).

Although heat cradles are no longer used for 'shock' treatment some advice can be given, based on current work, on the effects of injury on thermoregulation. Injured patients will cool rapidly especially if they are very young or old. This should be prevented as it will impose an unwanted metabolic burden. Injured patients obviously prefer a warm environment (Wilmore et al., 1975; Aulick et al., 1977; Hènane et al., 1981) and providing this will increase their comfort. A warm environment is particularly valuable in burn patients with a high obligatory evaporative loss from the burned surface. The latent heat of vaporization has to be supplied by the body and is a further large burden on the patient's metabolism. Although this cannot be circumvented, raising the external temperature $\left(<32^{\circ} \mathrm{C}\right)$ will reduce the heat production necessary to maintain the gradient between the body's core and the exterior. In all situations in which heat is being applied to patients steps must be taken to ensure that their blood volume is adequate. The water requirement of patients in the tropics are much greater than in the temperate zones.

We are not yet in a position to say what should be done, if anything, about the changes in the cardiovascular reflexes. As yet there are no indications as to whether the changes could be corrected by centrally acting drugs. Normality could be restored by cutting off the afferent nociceptive impulses which cause them. The full value of peripheral nerve blocks and regional anaesthesia has yet to be explored although there are results which show their corrective value (Kehlet et al., 1979, 1980). 
It should be remembered that injured patients do not show the normal cardiovasculam responses to movements such as tilting and this must be borne in mind when moving them on and off trolleys, into ambulances and in mountain and helicopter rescues (Waddell et al., 1975).

The changes in the homoeostatic cardiovascular reflexes affect some other aspects o $\overrightarrow{\overrightarrow{\underline{E}}}$ the management of the severely injured patient. The altered relationship between bloo $\mathbb{P}$ pressure and pulse rate means that the latter may not be such a good guide to changes i㕸. the patient's condition as in, say, the simple haemorrhage from a peptic ulcer. Despitळ this, changes in arterial pressure may still reflect changes in intracranial pressure sincê Little \& Öberg (1981) have shown that in the anaesthetized cat this response is unaffected by the level of baroreceptor activity.

The Defence Reaction and nociceptive inhibition of baroreceptor activity probably $\overrightarrow{\vec{\omega}}$ explain the hypertension so often seen very shortly after an injury in young people. Thi\$D is a normal response which will not persist. It should not be allowed to obscure the fact. that they may have lost a large amount of fluid from the circulation that needs replacing:Such patients should never be allowed to become hypotensive, there must never be anyer waiting for a fall in blood pressure before transfusion. The amount of fluid to be given is decided, quite separately, from information on the amounts of fluid loss associated with different injuries and from following the central venous pressure changes. This form of hypertension does not affect the prognosis unlike the hypertension sometimes seen in association with trauma during World War II which had a bad prognosis. The explanation is probably that the battle casualties were being studied some $10 \mathrm{~h}$ afeer wounding (Green et al., 1949; Grant \& Reeve, 1951) and the persistence of hypertenstion for such a long period meant that there was severe and widespread vasoconstriction which would interfere with the blood flow to essential organs, e.g. kidney (Green et $\overrightarrow{a l}$. $\bar{\partial}$ 1951).

It is possible that we are about to see an explosion of interest in the effects of periphera绾 trauma on the central nervous system with the ensuing development of the use of centrally acting drugs to correct the various disturbances. Indeed, the necessary agonists and antagonists are probably already available but there is still a large gap in our. understanding of what is happening and how it might be altered for the best.

\section{The Nutrition of the Injured Patient}

When the patient starts to recover from his injuries care must be taken of his nutrition. $\mathrm{He}$ is then going through the 'flow' phase and during this period which may last severaP weeks, there is an increased loss of nitrogen, 3-methylhistidine, creatine and other tissue $\frac{0}{3}$ derived metabolites in the urine. There is an accompanying loss of weight, insulin resistance, impairment of immunological defences and increased liability to infection:

These changes naturally require treatment. It has already been pointed out that the loss of nitrogen and creatine in the urine is positively related to the severity of the injury (ISS). Early operation with the removal of all dead tissue, reduction of fractures, etc. will itself tend to reduce the amount of catabolism set in motion by the injury. At the same time the nutritional requirements of the injured patient must be considered. The matter. cannot be left to take care of itself for these patients lack appetite and eat poorly on their own. The experience of metabolic measurements in injured patients shows that if the ISS 
exceeds 14 a conscious decision on the nutritional management should be made, for it is generally agreed that the weight loss should not exceed $10^{\circ}{ }_{0}$. Despite lack of appetite which may last up to three weeks, most patients with an ISS $<20$, particularly if they are normally young and active, can probably be persuaded to eat a high calorie $(3000 \mathrm{Kcal} /$ day $)$, high protein $(100 \mathrm{~g} /$ day $)$ diet. The nutritive value of milk should not be forgotten $(660 \mathrm{Kcal} / 1 ; 3.2 \%$ protein; $3.7 \%$ fat; $4.6 \%$ carbohydrate). While there is a lot of variety in individual requirements, those with large multiple injuries will probably require some assisted feeding. In these patients a decision should be made after $48 \mathrm{~h}$. By that time the early surgical manoeuvres will have been completed and the patient will have been adequately resuscitated in respect of fluid, electrolytes and erythrocytes. These questions must then be answered.

How many calories are required? The counsel of perfection is to measure the resting energy expenditure by indirect calorimetry and give 1.25-1.5 times the caloric output. Failing this it should be remembered that, except after burns, this output rarely exceeds $2000 \mathrm{Kcal} /$ day so that intakes of up to $2500-3000 \mathrm{Kcals} /$ day should be quite adequate. More may be required by the patient with extensive burns (Davies, 1982) but for general use the diets of $5000 \mathrm{Kcal}$ which used to be ordered are quite inappropriate.

What calorie sources should be given? Since there is never any difficulty in oxidizing fat a mixture of fat and carbohydrate should be given with fat supplying a third to half the total calories. Nitrogen is needed along with this and $14 \mathrm{~g} /$ day in the form of amino acids would probably be enough for most patients. Whether or not specific steps should be taken to counteract the insulin resistance is still a difficult problem. Insulin, along with glucose and potassium, may certainly be required for the emergency treatment of the 'sick cell' syndrome (Flear \& Singh, 1983), but the routine use of insulin requires further research. This is particularly the case for elderly patients where raised plasma concentrations of cortisol and insulin persist much longer after injury than in young patients. Part of the reduced sensitivity to insulin may be related to immobility (Blotner, 1945; Dolkas \& Greenleaf, 1977) and early movement must be encouraged.

How should the diet be given? The obvious answer is enterally and if the patient is unable to take sufficient food by mouth the first step is to give it by fine-bore naso-gastric tube. When this is not tolerated, and it is important to ensure an adequate intake, parenteral feeding will have to be used. A realistic assessment of the patient should be made and if it is thought that the other techniques will not be practical parenteral feeding should be adopted early and not put off until a last resort.

\section{CONCLUSION}

At a time when the value of research is frequently questioned the modest investment of research in trauma is yielding results which are leading to improvements in treatment. It must be emphasized that the type of research which is having this effect is frequently detailed and 'basic', involving laboratory experiment as well as clinical studies. It is also clear that much further research is needed before the treatment of the injured patient will be entirely satisfactory. 


\section{REFERENCES}

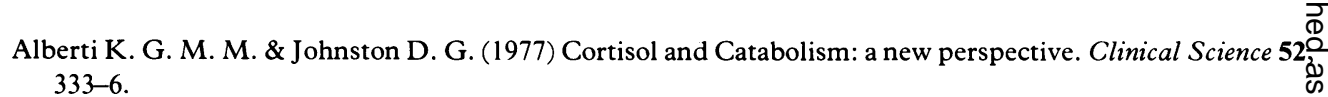

Allen J. P., Allen C. F. \& Greer M. A. (1973) Spinal cord pathways involved in tourniquet stimulation of ACTH secretion. Neuroendocrinology 13, 246-54.

Annotation (1977) Crush Injuries. British Medical fournal ii, 1244.

Aulick L. H., Wilmore D. W., Mason A. D. \& Pruitt B. A. (1977) Influence of the burn wound on periphera circulation in thermally injured patients. American fournal of Physiology 233, H520-6.

Baker S. P., O’Neil B., Haddon W. \& Long W. B. (1974) The injury severity score: a method for describing patients with multiple injuries and evaluating emergency care. fournal of Trauma 14, 187-96.

Baracos V., Rodemann H. P., Dinarello C. A. \& Goldberg A. L. (1983) Stimulation of muscle proteim degradation and prostaglandin $\mathrm{E}_{2}$ release by leucocyte pyrogen (interleukin-1). New England fournal of Medicine 308, 553-8.

Barton R. N. \& Little R. A. (1978) Effects of inhibition of adrenal steroidogenesis on compensation of fluid los and on survival after limb ischaemia in the rat. Fournal of Endocrinology 76, 293-302.

Barton R. N. \& Passingham B. J. (1980) Evidence for a role of glucocorticoids in the development of insulin

resistance after ischaemic limb injury in the rat. Fournal of Endocrinology 86, 363-70.
Barton R. N. \& Passingham B. J. (1982) Early responses to haemorrhage in the conscious rat: effectsoof corticosterone. American fournal of Physiology 243 R416-23.

Benedict C. R. \& Grahame Smith D. G. (1978) Plasma noradrenaline and adrenaline concentrations dopamine- $\beta$-hydroxylase activity in patients with shock due to septicaemia, trauma and haemorrhageo Quarterly fournal of Medicine NS 47, 1-20.

Black P. R., Brooks D. C., Bessey P. Q., Wolfe R. R. \& Wilmore D. W. (1982) Mechanisms of insulin resistanc® following injury. Annals of Surgery 196, 420-35.

Blotner H. (1945) Effect of prolonged physical inactivity on tolerance of sugar. Archives of Internal Medicine 75, $39-44$.

Bull J. P. (1975) The injury severity score of road traffic casualties in relation to mortality, time of death hospital treatment time and disability. Accident Analysis and Prevention 7, 249-55.

Bull J. P. (1978) Measures of severity of injury. Injury 9, 184-7.

Clowes G. H. A., George B. C., Villee C. A. \& Saravis C. A. (1983) Muscle proteolysis induced by a circulating peptide in patients with sepsis of trauma. New England fournal of Medicine 308, 545-52.

Colley C. M., Fleck A., Goode A. W., Muller B. R. \& Myers M. A. (1983) Early time course of the acute phasê protein response in man. Fournal of Clinical Pathology 36, 203-7.

Cuthbertson D. P. (1942) Post-shock metabolic response. Lancet i, 433-7.

Davies J. W. L. (1982) Physiological Responses to Burning Injury. London, Academic Press.

Davies C. L. \& Molyneux S. G. (1982) Routine determination of plasma catecholamines using reversed-phase $\frac{D}{O}$ ion pair high performance liquid chromatography with electrochemical detection. fournal of Chromatog raphy 231, 41-51.

Dible J. H. (1970) Napoleon's Surgeon. London, Heineman.

Dolkas C. B. \& Greenleaf J. E. (1977) Insulin and glucose responses during bed rest with isotonic and isometri£心 exercise. Fournal of Applied Physiology 43, 1033-8.

Flear C. \& Singh C. M. (1983) Sick-cell concept and hyponatraemia. In Handbook of Intensive Care. W. H. Baing $\& \mathrm{~K}$. Taylor (eds). London, Wright.

Folkow B. \& Neil E. (1971) Circulation. London, Oxford University Press.

Frayn K. N. (1977) The site of insulin resistance after injury. Endocrinology 101, 312-14.

Frayn K. N., Little R. A., Stoner H. B. \& Galasko C. S. B. (1983) To be published. 
Frayn K. N., Stoner H. B., Barton R. N., Heath D. F. \& Galasko C. S. B. (1983) Persistence of high plasma glucose, insulin and cortisol concentrations in elderly patients with proximal femoral fractures. Age $\mathscr{F}$ Ageing 12, 70-6.

Grant R. T. \& Reeve E. B. (1951) Observations on the general effects of injury in man. Medical Research Council Special Report Series 277.

Green H. N., Stoner H. B., Whiteley H. J. \& Eglin D. (1949) The effect of trauma on the chemical composition of the blood and tissues of man. Clinical Science 8, 65-87.

Green H. N., Stoner H. B., Whiteley H. J. \& Eglin D. (1951) A case of traumatic uraemia. British Fournal of Surgery 39, 80-4.

Hadfield J. M. \& Stoner H. B. (1983) Interactions between ethanol and the responses to injury. Fournal of Trauma 23, 518-22.

Hènane R., Bittel J. \& Banssillon V. (1981) Partitional calorimetry measurements of energy exchanges in severely burned patients. Burns 7, 180-9.

Hunter J. (1794) A treatise on the blood, inflammation and gunshot wounds. London, Nicol.

Irving M. H. (1983) Abdominal injuries. In The Basis and Practice of Traumatology. S. Hughes (ed.) pp. 49-63. London, Heineman.

Kehlet H., Brandt M. R., Hansen A. P. \& Alberti K. G. M. M. (1979) Effect of epidural analgesia on metabolic profiles during and after surgery. British Fournal of Surgery 66, 543-6.

Kehlet H., Brandt M. R. \& Rem J. (1980) Role of neurogenic stimuli in mediating the endocrine-metabolic response to surgery. Fournal of Parenteral and Enteral Nutrition 4, 152-6.

Kovách A. G. B., Rosell S., Sandor P., Koltáy E., Kovách E. \& Tomka N. (1970) Blood flow, oxygen consumption and free fatty acid release in subcutaneous adipose tissue during haemorrhagic shock in cortisol and phenoxybenzamine-treated dogs. Circulation Research 26, 733-41.

Lillehei R. C., Dietzman R. H., Motsay G. J., Beckmar C. B., Romero L. H. \& Shatney C. H. (1974) Growth of the concept of shock and review of present knowledge. In Steroids and Shock. T. M. Glenn (ed.) pp. $377-409$. Baltimore, University Park Press.

Little R. A. \& Öberg B. (1981) Arterial baroreceptor reflex function during elevation of intracranial pressure. Acta Physiologica Scandinavica 112, 27-32.

Little R. A., Randall P. E., Redfern W. S., Stoner H. B. \& Marshall H. W. (1983) To be published.

Little R. A. \& Stoner H. B. (1981) Body temperature after accidental injury. British fournal of Surgery 68, $221-4$.

Little R. A., Stoner H. B. \& Frayn K. N. (1981) Substrate oxidation shortly after accidental injury in man. Clinical Science 61, 789-91.

Mack E. \& Egdahl R. H. (1970) Adrenal blood flow and corticosteroid secretion in haemorrhagic shock. Surgery, Gynaecology E Obstetrics 131, 65-71.

Porte D. \& Robertson R. C. (1973) Control of insulin secretion by catecholamines, stress and the sympathetic nervous system. Federation Proceedings 32, 1792-6.

Randall P. E., Banks J. \& Little R. A. (1984) Medical (military) anti-shock trousers-a short review. Archives of Emergency Medicine 1, 39-51.

Redfern W. S., Little R. A., Stoner H. B. \& Marshall H. W. (1983) Effect of limb ischaemia on the blood pressure-heart rate reflex in the rat. To be published.

Stoner H. B. (1969) The effect of environment on the response to injury in the rat. Post-graduate Medical Fournal 45, 555-8.

Stoner H. B. (1976) An integrated neuro-endocrine response to injury. In Metabolism and the Response to Injury. A. W. Wilkinson \& D. P. Cuthbertson (eds) pp. 194-201. Pitman Medical.

Stoner H. B. (1977) The role of catecholamines in the effects of trauma on thermoregulation, studied in rats treated with 6-hydroxydopamine. British fournal of Experimental Pathology 58, 42-9.

Stoner H. B., Barton R. N., Little R. A. \& Yates D. W. (1977) Measuring the severity of injury. British Medical Fournal ii, 1247-9.

Stoner H. B., Frayn K. N., Barton R. N., Threlfall C. J. \& Little R. A. (1979) The relationship between plasma substrates and hormones and the severity of injury in 277 recently injured patients. Clinical Science 56, 563-73.

Stoner H. B., Heath D. F., Yates D. W. \& Frayn K. N. (1980) Measuring the severity of injury. Fournal of the Royal Society of Medicine 73, 19-22. 
Stoner H. B. \& Marshall H. W. (1975) Studies on the mechanisms of shock. The importance of central catecholaminergic neurones in the response to injury. British fournal of Experimental Pathology 56, 157-66.

Stoner H. B. \& Marshall H. W. (1977) Localization of the brain regions concerned in the inhibition of shivering by trauma. British fournal of Experimental Pathology 58, 50-6.

Stoner H. B. \& Marshall H. W. (1982) Neural pathways mediating the inhibition of shivering by nonthermal afferent impulses from ischaemic limbs. Experimental Neurology 78, 275-84.

Stoner H. B., Marshall H. W., Redfern W. S. \& Little R. A. (1983) Afferent pathways for the pressor reflexes from ischaemic muscle in the rat. To be published.

Stoner H. B. \& Matthews J. (1967) Studies on the mechanism of shock. Fat metabolism after injury. British fournal of Experimental Pathology 48, 58-65.

Tabor H. \& Rosenthal S. M. (1947) Body temperature and oxygen consumption in traumatic shock and haemorrhage in mice. American fournal of Physiology 149, 449-64.

Threlfall C. J., Maxwell A. R. \& Stoner H. B. (1983) Post-traumatic creatinuria. To be published.

Trueta J. (1944) War surgery of the extremities in the light of recent experience. Lancet 1, 651-3.

Vigaš M., Németh S. \& Jurčovičová J. (1973) The mechanism of trauma-induced inhibition of insulin release. Hormone and Metabolic Research 5, 322-4.

Waddell G., Scott P. D. R., Lees N. W. \& Ledingham I. McA. (1975) Effects of ambulance transport in critically ill patients. British Medical fournal i, 386-9.

Wilmore D. W., Orcutt T. W., Mason A. D. \& Pruitt B. A. (1975) Alterations in hypothalamic function following thermal injury. fournal of Trauma 15, 697-703.

Received 2 August 1983; accepted for publication 12 August 1983 